\title{
The Design and Implementation of English Online Video Teaching System
}

\author{
LI Meijing ${ }^{1, a}$ \\ ${ }^{1} \mathrm{Ji}$ Lin Business and Technology College, Changchun 130000,China \\ alimeijing@163.com
}

Keywords: Streaming Media, English Teaching, Instruct System

\begin{abstract}
With the computer network technology and multimedia digital technology development, especially the application and popularization of the Internet, as a result of the modern distance education network is a trend in the development of education in the future. In order to solve the educates can break through the limitation of traditional teaching resources, to achieve excellent education resources and teaching method is not limited by time and space, with the aid of network resources for teaching become an important direction of education reform. This paper carefully analyses the actual situation of network teaching application both at home and abroad, studies the use of streaming Media technology in the Flash Media Server platform to build the English online video teaching system based on streaming Media.
\end{abstract}

\section{Introduction}

English as an international communication language, is gradually penetrated into people's life. Whether study or work, at home or abroad, gradually increase the frequency of people need to use English in. Therefore, all kinds of English education institutions also arises at the historic moment. More famous include new Oriental education technology group, new channel international education group, Wall Street English, etc. Generally fall into these institutions teaching way of large or small class teaching, as well as one-on-one tutoring alone, provide professional English training for the students [1-2]. But such teaching methods, also has exposed the problems for students more, often crowded classroom, teaching lack of pertinence. While small-class teaching and individual coaching, expensive, most students are difficult to burden for a long time. Therefore, by means of Internet teaching method gradually developed.

Compared to the past teaching mode, network education has its unique advantages. First of all, the network teaching in the teaching time and teaching place more flexible. Don't need the classroom teaching, students only need a computer device connected to the Internet can learn, saves the round-trip time and money. Second, because do not need to rent space as a classroom, reduce the cost of the teaching, thus in teaching for education institutions have more autonomy. Third, because do not restricted by location, education institutions can use more foreign teacher resources. Many English speaking teachers, can give students in other countries in their own homes for online teaching. Thus, online English teaching has good prospects for development.

\section{Streaming media technology overview}

Streaming Media is the continuous time base of Streaming Media, such as video, audio, animation, or other multimedia file [3]. Streaming Media technology is a kind of continuous real-time transmission technology based on time, namely the continuous image, voice after compression treatment on the server, your visitors to download while watching, and without having to download the entire file. After the Streaming Media data stream transmission play at any time at any time, just some delay in the beginning. After a few seconds or a few seconds after startup latency, the user can on the local computer using the decompression device to extract multimedia files to play and watch [4]. 
Streaming media system is mainly can be divided into four parts, the media encoder, the media file storage, media servers and media player system architecture and the relationship between each part is shown in figure 1.Media technology is a comprehensive technology, it includes from streaming media system architecture, transmission quality control to the network protocol and a series of technology.

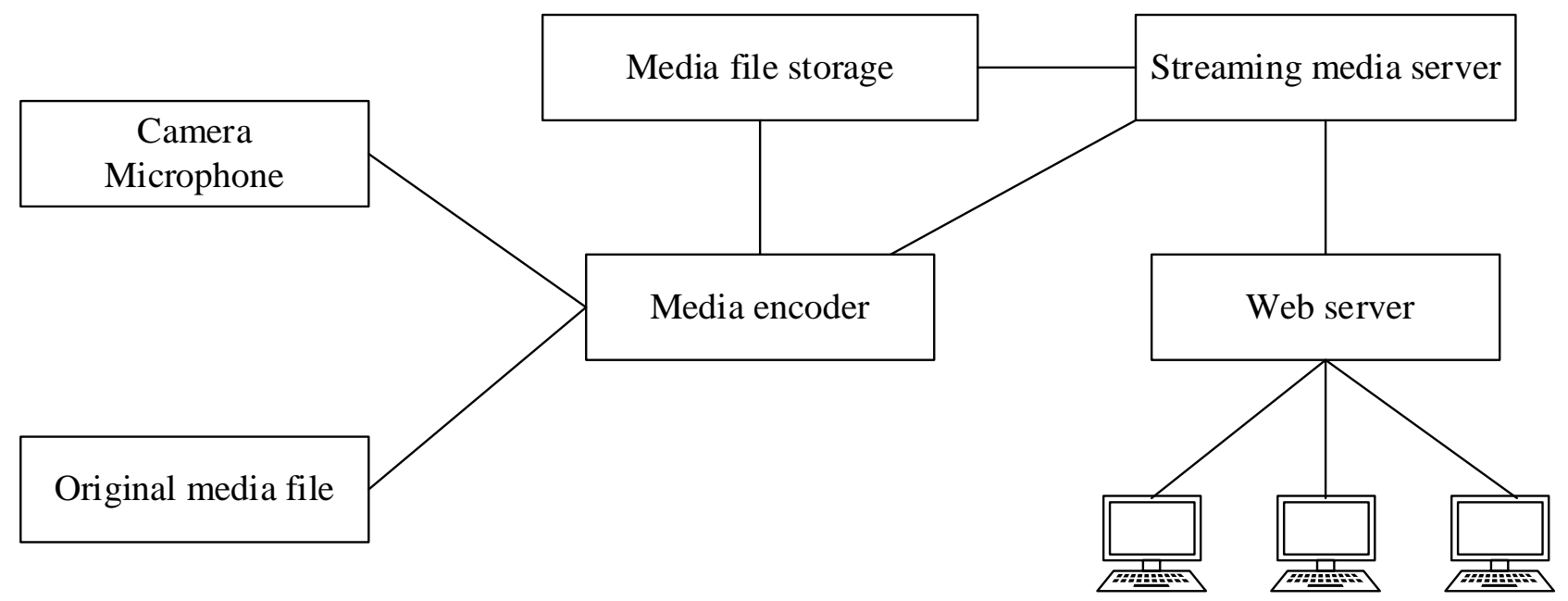

Media player

Figure 1. System architecture of streaming media

Body of the encoder. The original media file or camera acquisition in real-time data into suitable for network transmission media file formats, and streaming media files stored on the media server, or directly to the streaming media server.

The media file storage. Storage stream media file formats, generally USES the SCSI hard disk or disk array.

The media server. Response from a Web server to the user request, through the network transmission protocol will stream format of the file to the user's desktop.

The media player. Receive the network media data, and in the local broadcast.

\section{English online video teaching system requirements analysis}

With the development of China's economy and the progressive realization of modernization, more and more people want to go abroad for further study, IELTS teaching institutions more and more, but many of the fixed-point teaching institutions due to its own limitations and cannot meet the demand of market [5-6]. The emergence of the online video teaching provides a solution to this problem, because the market almost no online video teaching platform for English, so English teaching has a good profit, there is a huge business opportunity. User requirements description is the user's goals, or user requirements system must be able to complete tasks. Users can use the system is described that is to say, the user needs to do something. The system for the user role is divided into three major functional modules, student module, teacher module, background management module, as shown in figure 2.

In system engineering and software engineering, the requirements analysis is the creation of a new or change an existing system or product, determine the purpose of the new system, scope, definitions, and function have to do all the work. Demand analysis is a key process in software engineering. In this process, the system analyst and software engineers to determine the needs of the customers. Only in determining the need before they can analyze and seek new system solutions. 


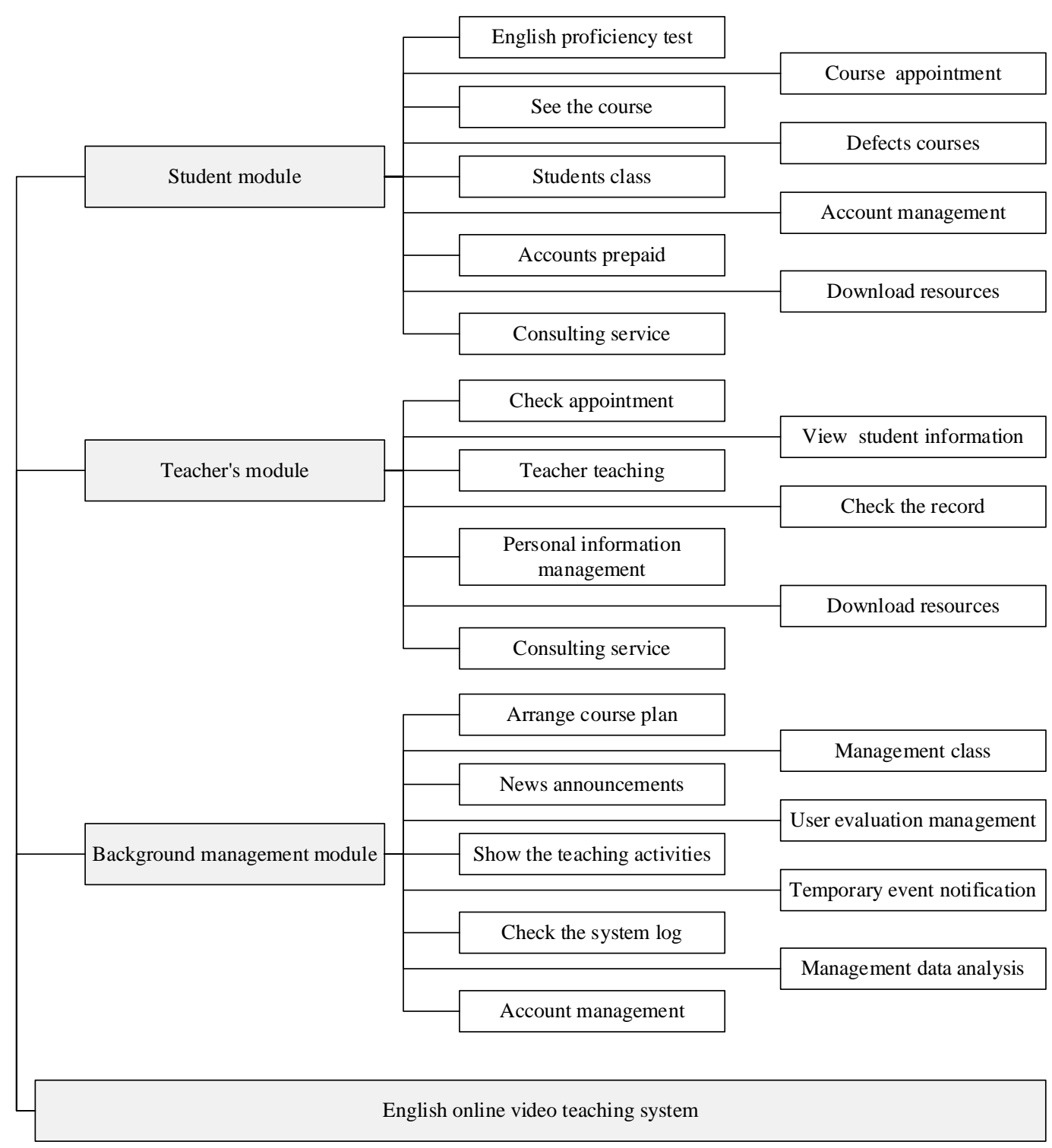

Figure 2. Function module of English online video teaching system

\section{English online video teaching system design based on streaming media}

In this paper, the English online video teaching system based on streaming media has carried on the design and implementation, design the teachers teaching video, teachers courseware management and client and decompression is overall framework, as shown in figure 3. System design goal is to give full play to the Flash Media Serve the advantage of streaming Media services, to support multiple data stream transmission at the same time, that can have multiple network classroom "at the same time can also be completed at the same time the corresponding management work, such as the network classroom and teacher, student registration, student queries of each network classroom teaching content, choice, etc.

Online video teaching system is mainly composed of the online classroom, VOD system, player, late editing system, billing system and encryption tool, each module's function is as follows:

Online classroom. The classroom instructor computer video and audio information record for streaming media files, to provide later replay or online on demand. Online classroom is the core modules of this system, mainly including streaming video and chat room module, we will be in the fourth chapter details the module design and implementation of the scheme.

VOD system. Provide on-demand features, combined with the player module streaming VOD server to realize the streaming media files and other various media files. 
Player. Not only can receive real-time online classroom are on course, can also play online provide on-demand courseware on demand in the server. Player is based on Flash design of general module, users do not need to install additional software.

Late editing system. Provide offline editing function, FLV file can be properly cut, make record courseware has more complete application effect of teaching.

Billing system. The billing system is the extension of system design. The online classroom, courseware associated with teachers' accounts, implementation to collect fees, additional features such as a discount. And provide the dock with the school finance system interface.

Encryption tool. Provided based on the server and client encryption module, can publish Web courseware for server access control and client packaged encryption, network and CD-ROM transmission can be guaranteed effectively in the copyright protection of media resources.

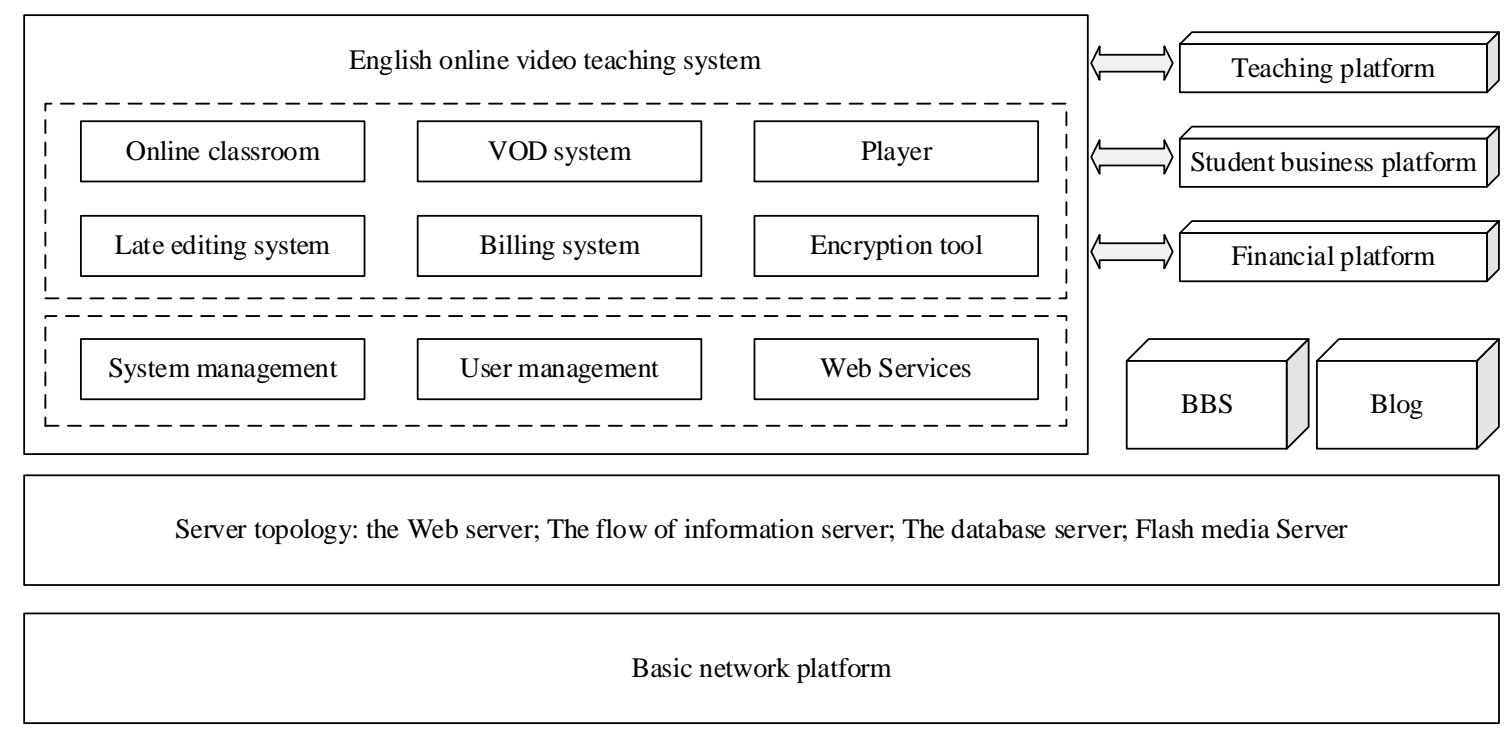

Figure 3. The stricture of English online video teaching system based on streaming media

\section{Conclusion}

Using the Internet to online video teaching, with its flexible teaching methods and rich teaching contents characteristics attract many users. Different from traditional teaching methods, using the Internet for online teaching of teaching time and teaching place limit is very small. Students can choose according to oneself circumstance learning content, is a kind of demand oriented approach to learning. In the face of such a huge market, a lot of education training institutions began to develop their own online teaching platform, at the same time of integrating the teaching resources to expand market share. This article is based on streaming media technology implements a set of complete English online video teaching system of teaching. Teaching English online video teaching system as the basis of distance teaching platform, realizes the network based remote teaching activities, has very important significance.

\section{References}

[1] Sockett G, Toffoli D: ReCALL, 2012, 24(02): 138-151.

[2] Ludwick D A, Doucette J: International journal of medical informatics, 2009, 78(1): 22-31.

[3] Liu I F, Chen M C, Sun Y S: Computers \& Education, 2010, 54(2): 600-610.

[4] Masaoka M: U.S. Patent Application 12/804,519[P]. 2010-7-23.

[5] Squire K: Teachers College Press. 1234 Amsterdam Avenue, New York, NY 10027, 2011.

[6] So H J, Lossman H, Lim W Y: Australasian Journal of Educational Technology, 2009, 25(3): 440-457. 